\title{
Biomedical Engineering Accredited Undergraduate Programs: 4 Decades of Growth
}

I am pleased to continue the series of Biomedical Engineering Society (BMES) presidential editorials in our lead journal, the Annals of Biomedical Engineering. With the privilege of this forum, I want to take the opportunity to provide data to document the astounding growth of academic programs in Biomedical Engineering and the number of remarkable students that we are preparing. The focus in this short piece is on ABET accredited undergraduate programs in the US, the students they serve, and the faculty that lead their learning.

The table of ABET accredited undergraduate programs tells an interesting story (data from Ref. 3). In the 1970s, 7 universities had established accredited undergraduate programs in Bioengineering/Biomedical Engineering (referred to hereafter as BME). Although each new department/program has a unique genesis story, several of the early programs developed from Electrical Engineering departments that were focused on measurement and instrumentation. The BME programs were mostly at private universities with schools/colleges of engineering and associated medical schools. The story was similar for many of the 13 new accredited BME programs in the 1980s, with comparable initial conditions, but additional program births from mechanical and materials oriented programs. Only 4 new programs were accredited in the 1990s (see Table 1 with data from Ref. 3).

Note that the Whitaker Foundation was very active from the 1990s until 2006 with an emphasis on biomedical engineering education and the development of departments. ${ }^{2}$ The Foundation recognized that in the academy, centers and institutes may come and go, but departments have relative permanence. Whitaker Foundation funding encouraged matching university investments for developing new BME departments and programs.

It should also be noted that programs cannot be accredited until a student graduates with a degree from the program. Only then can the program submit an ABET self-study, after which the program hosts an ABET evaluator. These visits are generally in the autumn; programs are notified of the outcome during the following summer. Thus, in practice, there is at least a 4-year time lag between the degree program initiation and accreditation; generally it is somewhat longer.
These and other factors contributed to an astounding 51 new ABET accredited BME BS programs between 2000 and 2009. Many of these new programs emerged from chemical engineering activities, with a heavy new emphasis on tissue engineering. Many state universities were also represented. Since 2010, 17 additional BME programs have been accredited. As of January 2015, there were 92 ABET accredited BS programs in Bioengineering/Biomedical Engineering. ${ }^{3}$

Financial opportunities, expansion of research applications for engineering methods and techniques to biomedical problems, and the associated eruption of the quantity and quality of quantitative life science investigations have driven the growth of academic BME programs. So, too, has intense student interest.

Chart 1, with data from the American Society for Engineering Education, shows the overall linear population growth of full time undergraduate students in BME $\left(r^{2}=0.993\right)$, over the past 15 years. ${ }^{4}$ During this period, the population of undergraduate students grew by 1593 each year, despite the fact that many programs have had to cap their enrollment based on limitations of faculty size and facilities.

Meanwhile, the growth of tenure/tenure-track faculty is shown in Chart 2, also using ASEE data. ${ }^{4}$ It shows linear growth $\left(r^{2}=0.983\right)$ since 2001, with 66.9 new tenure track BME faculty added each year. These overall numbers show a current student faculty ratio of 19.7:1. This gross calculation needs interpretation: some programs count freshmen, some do not. Some programs include professors of the practice, and these numbers are not captured in the tenure track faculty count. Nonetheless, the overall ratio may be useful for a rough estimate of faculty resources used by the existing programs. Department chairs sometimes discuss aiming for 3-5 BS degrees awarded per faculty member annually, depending on the nature of the department and the spectrum of primary faculty activities between teaching intensive and research intensive.

Unanswered by these charts is the question of what happens to these students once they graduate? In the early years of BME undergraduate programs, the anecdotal expectation was that $1 / 3$ would go to medical school, $1 / 3$ to graduate school, and $1 / 3$ to industry. Unfortunately, although individual programs track graduates, the last reliable summary data from the 
TABLE 1. Timeline for growth of ABET accredited BS programs in bioengineering and biomedical engineering.

\begin{tabular}{|c|c|c|c|}
\hline Duke University & 1972 & Rose-Hulman Institute of Technology & 2005 \\
\hline Rensselaer Polytechnic Institute & 1972 & Rutgers University & 2005 \\
\hline Brown University & 1973-2000; 2004 & Saint Louis University & 2005 \\
\hline University of Illinois at Chicago & 1976 & University of Alabama, Birmingham & 2005 \\
\hline Case Western Reserve University & 1977 & University of Connecticut & 2005 \\
\hline Texas A\&M University & 1977 & University of Texas at Austin & 2005 \\
\hline Louisiana Tech University & 1978 & Lehigh University & 2006 \\
\hline Tulane University & 1981 & Purdue University & 2006 \\
\hline Northwestern University & 1982 & Binghamton University, SUNY & 2006 \\
\hline University of Pennsylvania & 1982 & The George Washington University & 2006 \\
\hline Boston University & 1983 & University of California, Irvine & 2006 \\
\hline Marquette University & 1983 & University of Virginia & 2006 \\
\hline The Johns Hopkins University & 1983 & University of Washington & 2006 \\
\hline University of lowa & 1984 & Washington State University & 2006 \\
\hline Arizona State University & 1986 & Bucknell University & 2007 \\
\hline Syracuse University & 1987 & Illinois Institute of Technology & 2007 \\
\hline University of California, San Diego & 1987 & Pennsylvania State University & 2007 \\
\hline Milwaukee School of Engineering & 1988 & University of Central Oklahoma & 2007 \\
\hline The Catholic University & 1988 & University of Maryland & 2007 \\
\hline Wright State University & 1988 & Florida Gulf Coast University & 2008 \\
\hline Vanderbilt University & 1990 & Indiana Univ. - Purdue Univ. Indianapolis & 2008 \\
\hline University of Miami & 1995 & Stevens Institute of Technology & 2008 \\
\hline The University of Toledo & 1998 & The University of Memphis & 2008 \\
\hline University of Pittsburgh & 1999 & University of Louisville & 2008 \\
\hline Drexel University & 2000 & University of Southern California & 2008 \\
\hline The University of Akron & 2000 & University of Utah & 2008 \\
\hline University of California, San Diego & 2001 & City University of New York, City College & 2009 \\
\hline University of Tennessee & 2001 & Clemson University & 2009 \\
\hline Worcester Polytechnic Institute & 2001 & Rice University & 2009 \\
\hline North Carolina State University & 2002 & Indiana Institute of Technology & 2010 \\
\hline University of Hartford & 2002 & The Ohio State University & 2010 \\
\hline University of Minnesota & 2002 & Tufts University & 2010 \\
\hline University of Rochester & 2002 & Union College & 2010 \\
\hline Virginia Commonwealth University & 2002 & University of South Carolina & 2010 \\
\hline Georgia Institute of Technology & 2003 & George Mason University & 2011 \\
\hline Michigan Technological University & 2003 & Lawrence Technological University & 2011 \\
\hline University of Cincinnati & 2003 & The College of New Jersey & 2011 \\
\hline University of Wisconsin, Madison & 2003 & University of California, Davis & 2011 \\
\hline Florida International University & 2004 & University of California, Riverside & 2011 \\
\hline Oregon State University & 2004 & University of Rhode Island & 2011 \\
\hline Stony Brook University, SUNY & 2004 & University of the Pacific & 2011 \\
\hline University of Michigan & 2004 & Miami University & 2012 \\
\hline Washington University & 2004 & University of Illinois at Urbana-Champaign & 2012 \\
\hline Western New England University & 2004 & University of Maine & 2012 \\
\hline Columbia University & 2005 & Wichita State University & 2012 \\
\hline New Jersey Institute of Technology & 2005 & University of California, Los Angeles & 2013 \\
\hline
\end{tabular}

American Institute of Medical and Biological Engineers (AIMBE) Academic Council survey results are somewhat stale. Those data are from the 2006-2007 academic year, when programs pooled data from 1352 graduates. The results showed $41 \%$ of the students entering industry, $35 \%$ entering graduate school, $16 \%$ entering medical school, and $8 \%$ other (seeking job, unknown, etc.). Outcomes vary based on the university, location (urban or rural), program emphasis, and they have changed over time. These data may nevertheless give a useful "rule of thumb" for universities considering the addition or expansion of undergraduate BME programs, until fresh data are collected.
Of course, the linear growth of recent history cannot continue indefinitely. The academic roots for most programs come from universities with colleges/schools of engineering and/or colleges/schools of medicine. It appears that there are approximately 320 colleges/ schools of engineering in the US offering BS engineering degrees and 121 colleges/schools of medicine. Most, but not all, universities with colleges/schools of medicine also have colleges/schools of engineering. So, with 92 accredited programs already, one can guess that over the next 25 years, the total number of ABET accredited undergraduate programs in the US may rise to a total of $150-175$ ? 


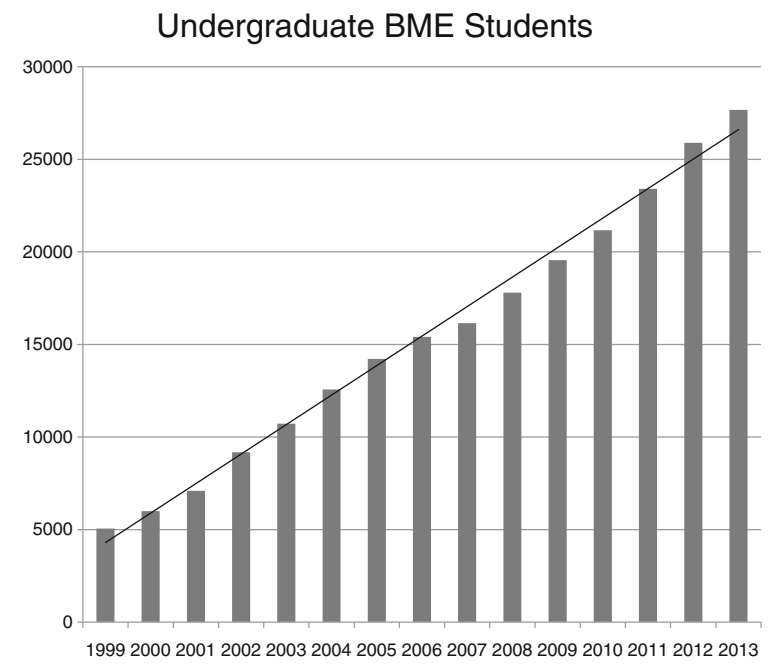

CHART 1. Linear growth of undergraduate enrollment in BME over the past 15 years; an increase of 1593 new students per year.

BME Faculty: Tenure/Tenure Track

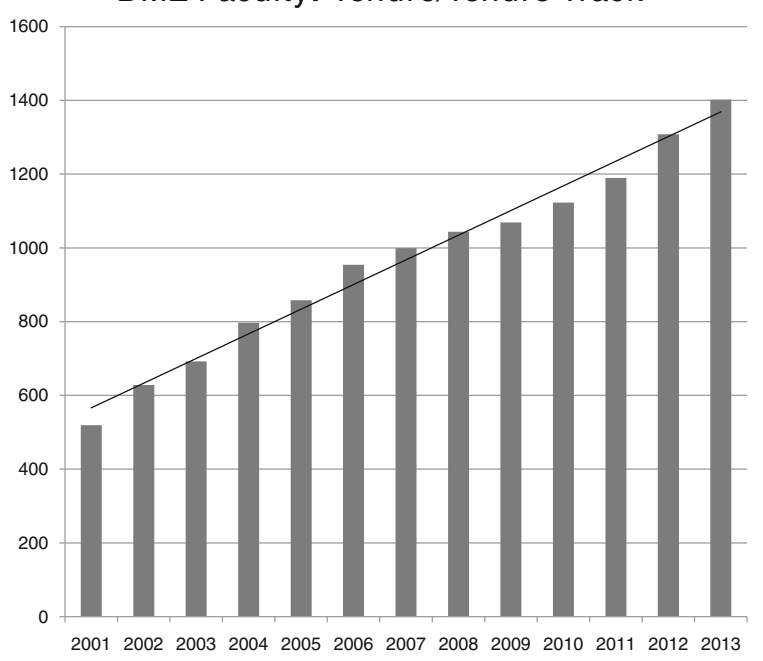

CHART 2. Linear growth of tenure/tenure track BME faculty; an increase of 67 new faculty members per year.
Finally, the US Department of Labor Statistics projects job outlooks for many occupations. The current outlook for Biomedical Engineers is for $27 \%$ job growth between 2012 and 2022, over twice the overall outlook of $11 \%$ for all occupations. ${ }^{1}$ Time will tell!

Until then, it may be worth pausing to note the great success that has accompanied the launch of our accredited undergraduate interdisciplinary academic programs since 1972.

\section{ACKNOWLEDGMENTS}

I very much appreciate the comments that Peter G. Katona made on an earlier draft of this note.

\section{REFERENCES}

${ }^{1}$ http://www.bls.gov/ooh/architecture-and-engineering/biomedi cal-engineers.htm.

${ }^{2}$ Katona, P. G. The Whitaker Foundation: The End Will Just Be the Beginning. IEEE Trans. Med. Imaging 21:845-849, 2002.

${ }^{3}$ www.abet.org.

${ }^{4}$ Yoder, B.L., "Engineering by the Numbers," in http://www. asee.org/papers-and-publications/publications/14_11-47.pdf, 2014.

\section{RICHARD T. HART}

The Ohio State University, Columbus, OH, USA

Electronic mail: hart.322@osu.edu 